JOURNAL OF

APPLIED

CRYSTALLOGRAPHY

ISSN 1600-5767

\section{A new method for quantitative phase analysis using X-ray powder diffraction: direct derivation of weight fractions from observed integrated intensities and chemical compositions of individual phases. Corrigendum}

\section{Hideo Toraya*}

Rigaku Corporation, 3-9-12 Matsubara, Akishima, Tokyo, 196-8666, Japan. *Correspondence e-mail: toraya@rigaku.co.jp

Keywords: X-ray powder diffraction; quantitative phase analysis; direct derivation; intensity-composition formula

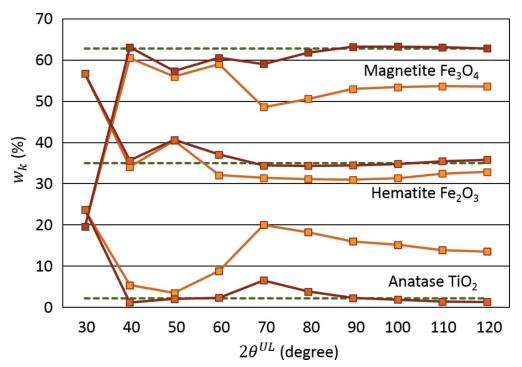

C 2017 International Union of Crystallography
Erroneous equations in the paper by Toraya [J. Appl. Cryst. (2016), 49, 15081516] are corrected.

In the paper by Toraya (2016), equations (9) and (10) on page 1511 were erroneously given. The correct equations are as follows:

For $k^{\prime}=k$

$$
\frac{\partial w_{k}}{\partial I_{j k}}=w_{k}\left(1-w_{k}\right) G_{j k}\left(\sum_{j=1}^{N_{k}} I_{j k} G_{j k}\right)^{-1} .
$$

For $k^{\prime} \neq k$

$$
\begin{aligned}
\frac{\partial w_{k}}{\partial I_{j k^{\prime}}}= & -w_{k} w_{k^{\prime}} G_{j k^{\prime}}\left(\sum_{j=1}^{N_{k^{\prime}}} I_{j k^{\prime}} G_{j k^{\prime}}\right)^{-1} \cdot \\
\text { s.u. }\left(w_{k}\right)= & w_{k}\left[\left(1-2 w_{k}\right)\left(\sum_{j=1}^{N_{k}} I_{j k} G_{j k}\right)^{-2} \sum_{j=1}^{N_{k}} G_{j k}^{2} \sigma^{2}\left(I_{j k}\right)\right. \\
& \left.+\sum_{k^{\prime}=1}^{K} w_{k^{\prime}}^{2}\left(\sum_{j=1}^{N_{k^{\prime}}} I_{j k^{\prime}} G_{j k^{\prime}}\right) \sum_{j=1}^{-2} G_{j k^{\prime}}^{2} \sigma^{2}\left(I_{j k^{\prime}}\right)\right]^{1 / 2} .
\end{aligned}
$$

The amounts of underestimation by the erroneous equations were in the range of $18-37 \%$ for individual test samples and $24 \%$ in grand average.

\section{References}

Toraya, H. (2016). J. Appl. Cryst. 49, 1508-1516. 